\title{
La resistencia autobiográfica de Mario Levrero: compromiso versus autoficción en sus diarios
}

\author{
Álvaro Luque Amo ${ }^{1}$
}

Resumen. En la última parte de su obra, con la publicación de tres diarios personales, Mario Levrero problematiza los límites entre el discurso referencial y el ficcional. Estos diarios han sido asociados con frecuencia a los géneros autoficcionales, pero el estudio de sus rasgos puede revelar su idiosincrasia autobiográfica, lo que va a representar la principal tesis de este trabajo. A partir de esta hipótesis, se analizan los diarios de Levrero con el objetivo de establecer las diferencias y los límites entre autobiografía y autoficción, terreno confuso en el campo de los estudios literarios. A ello contribuirá, a su vez, el estudio del compromiso de verdad que el autor propone en estas obras, el cual estará apoyado en las tesis de Manuel Alberca y Michel Foucault.

Palabras clave: Levrero; diario literario; autobiografía; autoficción.

[en] The autobiographical resistance of Mario Levrero: commitment versus autofiction in his diaries

\begin{abstract}
In the last part of his work, with three personal diaries, Mario Levrero problematizes the limits between referential and fictional discourse. The three diaries have been categorized frequently with the label of autofiction; on the contrary, the present work maintains their autobiographical character. Derived from this, these diaries are a good example to establish the limits between autobiography and autofiction, a confusing terrain in the field of literary studies. To demonstrate this, the analysis is based on the theses of Manuel Alberca and Michel Foucault, with the aim of examining the commitment to truth that the author proposes in his diaries.
\end{abstract}

Keywords: Levrero; literary diary; autobiography; autofiction.

Sumario: 1. Presupuestos teóricos: el coraje de decir la verdad. 1.1. Lo autobiográfico frente a lo autoficcional. 1.2. Manuel Alberca y el concepto de antificción.1.3. La parresía: Foucault y el coraje de decir la verdad (autobiográfica). 2. La autobiografía diarística de Mario Levrero. 2.1. La obra diarística de Mario Levrero. 2.2. Diario de un canalla. 2.3. El discurso vacío. 2.4. La novela luminosa.

3. Conclusiones.

Cómo citar: Luque Amo, A. (2021) La resistencia autobiográfica de Mario Levrero: compromiso versus autoficción en sus diarios, en Anales de Literatua Hispanoamericana 50, 381-392.

\section{Presupuestos teóricos: el coraje de decir la verdad}

\subsection{Lo autobiográfico frente a lo autoficcional}

Ha habido en las pasadas décadas una creciente confusión a la hora de establecer los límites entre literatura autoficcional y literatura autobiográfica. En el ámbito de los estudios literarios, solo en los últimos años algunos autores se han aproximado a una verdadera diferenciación entre ambas categorías.

Lo autoficcional surge, no por casualidad, muy pocos años después de que en 1975 Philippe Lejeune acuñara (Lejeune, 1994) el que hasta ahora ha sido el concepto más célebre en los estudios sobre autobiografia, el denominado pacto autobiográfico. Este pacto, que bautiza el compromiso de verdad establecido entre autor y lector de la obra autobiográfica, es respondido pocos años después por Serge

\footnotetext{
${ }^{1}$ Universidad de Granada. España.

E-mail: aluqueamo@ugr.es
} 
Doubrovsky ${ }^{2}$, quien recurre al nombre de autoficción para definir a su novela Fils (1977) y abarcar con esa definición a aquella obra autobiográfica cuyos referentes se difuminan en la obra ficcional de carácter normalmente novelístico.

Aquí nace una dualidad, lo autoficcional frente a lo autobiográfico pactado, que en numerosas ocasiones ha generado confusión teórica. Esta confusión la resume Ana Casas al describir lo autoficcional como un cajón de sastre que abarca textos tales como las autobiografías que utilizan formas poco habituales — como el uso de la tercera persona- o aquellas que incluyen forman paródicas; los textos autobiográficos en donde no hay identificación expresa entre autor y personaje; aquellos que presentan una voz narradora propensa a la digresión o al comentario atribuible al autor; o incluso los relatos de autor ficcionalizado en donde se incluyen las suficientes rupturas de la verosimilitud realista como para considerarlo novela (Casas, 2012: 1011). A este caos terminológico se le añade, además, la intención de algunos autores por cuestionar los cimientos de la ficción tradicional —en el contexto español se podría hablar de Enrique Vila-Matas, quien emplea novelas como París no se acaba nunca (2003) para desafiar algunos preceptos de la autobiografía tradicional; y en el contexto internacional de Michel Houellebecq, que hace lo propio en El mapa y el territorio (2011) - , así como por desdibujar la referencialidad de su Yo autobiográfico a través de la retórica novelística, que provoca en última instancia el cuestionamiento de la voluntad de verdad que hay en todo texto autobiográfico.

Incluso con estos inconvenientes, sin embargo, y como se decía, algunos autores inciden en la necesidad de establecer unos límites entre las dos formas y, lo que es más importante, en la existencia de estos límites. Esto viene a indicar Jacques Lecarme cuando señala, a propósito de la principal diferencia entre autoficción y autobiografía, que la primera se trata de un relato cuyo autor comparte identidad con el narrador y el protagonista de la obra, y cuyo título genérico indica que se trata de una novela (Lecarme, 1993: 227). Lecarme, aquí, emplea dos elementos remarcables: en primer lugar, utiliza el concepto de identificación de Lejeune para referirse a la coincidencia nominal entre autor, narrador y protagonista; en segundo lugar, identifica novela con narración fabulada y extrae de ello la gran diferencia entre autobiografía y autoficción: esta última es novela - y por lo tanto narración que carece de referencialidad - y la primera no.

Esta diferencia se repite en la definición de Alicia Molero, una de las teóricas que más ha profundizado en esta cuestión:

La autoficción surge de la intención de abrir dudas en el lector por parte de un escritor poéticamente interesado en hacer caer las barreras entre discurso histórico y ficticio. En la práctica, se trata de anteponer un artilugio retórico donde tenga cabida lo biográfico (hechos, evocaciones y reflexiones personales); de este modo el discurso referido a sí mismo tendrá lugar dentro de una situación narrativa supuesta, convirtiendo el enunciado en una ficción (Molero, 2016).

Como puede observarse, la diferencia fundamental entre autoficción y autobiografía estriba en que en la primera el autor difumina las barreras entre lo factual y lo ficcional, y, esto es lo más importante, no se compromete a decir la verdad. La promesa autobiográfica, así, queda desdibujada, y el autor no se hace cargo de esas posibilidades de verdad que el lector pueda encontrarse al paso de su lectura. Para aceptar esta diferencia, sin embargo, es necesario suscribir lo expuesto por Lejeune a la hora de establecer el pacto autobiográfico, puesto que, de lo contrario, la diferencia entre lo autoficcional y lo autobiográfico se diluirá en el texto a favor siempre de lo meramente novelesco ficcional, nunca de lo referencial.

En estas coordenadas, lo interesante es destacar esta responsabilidad del autobiógrafo como elemento de diferenciación respecto a la autoficción, que precisamente lo que busca es sortear esta responsabilidad, este compromiso ético. Como señala Alicia Molero, "al contrario que el del autobiógrafo, el objetivo del novelista está en hablar de sí mismo sin responsabilizarse por ello del enunciado" (Molero, 2016).

Sostener lo anterior, sin embargo, no implica plantear el texto autobiográfico como antítesis del texto ficcional. En este sentido, están fundamentadas las sospechas posmodernas que plantean la dificultad de concebir una correspondencia exacta entre el Yo empírico y el Yo textual (Man, 1991). El sujeto que construye el texto autobiográfico, modelado a partir de palabras como ocurre exactamente en una novela,

\footnotetext{
${ }^{2}$ Al parecer, y como testimonia el propio Lejeune (1994: 178), Doubrovsky le escribió una carta en la que reconocía haber leído sus teorías, hasta el punto de verse influenciado por estas en la redacción de Fils y escribir en cierto modo con el objetivo de contradecir una afirmación del propio Lejeune. Este último señalaba que no había encontrado ningún ejemplo de obra en la que se produjese una identidad entre autor, narrador y personaje, y al mismo tiempo fuese una ficción. Para rellenar este supuesto hueco, Doubrovsky acuña el concepto de autoficción.
} 
deriva sin lugar a dudas en personaje, cumpliendo aquella máxima esbozada por Ricoeur cuando aseguraba, irónicamente, que algo muy sencillo separa a la vida y a la narración: la primera se vive, la segunda se escribe (Ricoeur, 2006: 15). Ahora bien, si el Yo autobiográfico tiene independencia sobre el Yo real y, por tanto, cierta capacidad de ficcionalización, ¿qué diferencia exactamente al texto autobiográfico del texto autoficcional? Y esta es la respuesta que desde nuestro punto de vista fundamenta esta diferencia: el compromiso de decir verdad autobiográfica ${ }^{3}$.

En esta línea, un autor como Ángel Loureiro ha desarrollado, basándose en las teorías de Levinas, una teoría del texto autobiográfico sustentada en este compromiso; según su postura, el Yo autobiográfico "se constituye como respuesta al otro y como responsabilidad hacia ese otro" (Loureiro, 2001: 136). Pero ha sido otro especialista como Manuel Alberca quien ha ofrecido una propuesta de interpretación más interesante para el desarrollo de este artículo.

\subsection{Manuel Alberca y el concepto de antificción}

En su último libro, publicado en 2017, Manuel Alberca ha esbozado una teoría de la escritura autobiográfica que intenta delimitar los límites entre autobiografía y ficción y, sobre todo, denunciar los excesos de ciertas modas de la literatura actual.

Si bien tras la aparición en 2007 de su libro El pacto ambiguo, Alberca ha sido considerado habitualmente el padre de la teoría autoficcional en el ámbito hispánico, rara vez se han destacado los matices negativos que tienen muchas de sus aportaciones. En este sentido, Alberca ha querido partir aquí de una actitud muy clara respecto a lo autoficcional que resume con las siguientes palabras: "Me cansa ya la autoficción, y [...] los años comienzan a darme una visión distinta de la literatura" (Alberca, 2017: 306).

Manuel Alberca intenta desarrollar el camino inverso al de Doubrovsky: plantear así la existencia de un tipo de texto, de carácter autobiográfico, que se construya precisamente haciendo un alarde de esa responsabilidad autobiográfica. Alberca habla así, recurriendo a Lejeune una vez más, del concepto de antificción. Lejeune aplica este concepto precisamente a una forma como el diario, cuyo narrador, al no distanciarse suficientemente de los hechos desde un punto de vista temporal, se vería imposibilitado para falsificar los mismos, de tal manera que construiría una "antificción" (Lejeune, 2007). Alberca, desarrollando el concepto, engloba dentro de la antificción a una serie de autores que optan por contar su vida o un episodio de esta, sin inventar nada, sin dotar a sus historias de elementos fabulados. Alberca diferenciaría, por tanto, entre los autores que dejan espacio a la ambigüedad, cultivadores de la autoficción, y los que declararían su compromiso con la verdad de acuerdo a diferentes fórmulas, cultivadores de lo autobiográfico.

Frente a los abusos de lo autoficcional, pues, Alberca opta en La máscara o la vida por preferir obras que priman el deseo por expresar la verdad autobiográfica de su autor, por someterse al compromiso de realidad. Lo antificcional, más que un género, es empleado como un discurso que tiene "la predisposición literaria a contar la verdad y solo la verdad, que excluye radicalmente la libertad o tentación de inventar que pueden tener algunos autores de la autoficción" (Alberca, 2017: 322). La apuesta de Alberca es clara: la elección de un texto que no cae en el espacio de la incertidumbre posmoderna respecto a lo autobiográfico; un texto que, en definitiva, no necesita la muleta de la ficción para ser recibido y celebrado por el sistema literario.

Hay en la posición de Alberca, sin embargo, algo que debe ser matizado. El nombre de antificción remite, a nuestro juicio, a un enfrentamiento con el estatuto ficcional del texto, algo que parece negar las posibilidades ficcionales del Yo autobiográfico y puede justificar las dudas de los escépticos. Desde nuestro punto de vista, en cambio, el texto autobiográfico es tan interesante porque se mueve en ese terreno resbaladizo situado entre lo ficcional y lo no ficcional y representa a un autor que pugna por no renunciar a ninguna de las dos lecturas de su texto. Si bien es cierto que Alberca no desarrolla este punto, el uso de un término como antificcional induce a enfrentar autobiografía y ficción. Por ello, lo más interesante de este

\footnotetext{
${ }^{3}$ Al usar el término verdad autobiográfica se intenta concretar una aplicación del difuso término verdad al terreno de la escritura o literatura autobiográfica. Se puede partir de una distinción muy útil, proporcionada por Gustavo Bueno, entre las nociones de verdad impersonal y personal. Las verdades impersonales, «aquellas en las cuales el sujeto operatorio se encuentra formalmente segregado de las figuras de las identidades que puedan ser probadas como constitutivas de la verdad», se diferencian de las personales, que son aquellas «en las cuales el sujeto operatorio (humano o animal) se mantiene formalmente presente (aunque en distintos grados) en las figuras constitutivas de la verdad» (Bueno, 2000: 280-281). Entre estas últimas, Bueno trata las verdades normativas, en cuyo subgrupo se encuentra la verdad-coherencia, que sería la más cercana al discurso autobiográfico entendiéndolo en las coordenadas de Lejeune. El autobiógrafo se compromete, según el pacto autobiográfico, con la narración de su verdad, la verdad de sus vivencias, que es una verdad personal en la que él se encuentra presente en todo momento y respecto a la que se mantiene coherente — por medio de ese contrato — en lo concerniente al lector. Tal es la verdad autobiográfica.
} 
término redunda sin lugar a dudas en su capacidad para recoger la intención por parte de ciertos autores de comprometerse a narrar unos hechos verdaderos.

Esta intención, claro, no se opone a la posible interpretación ficcional del texto autobiográfico. Sencillamente alude a una suerte de coraje por decir la verdad que residiría, según esta tesis, en los textos autobiográficos; algo que podrá entenderse mucho mejor en relación con las investigaciones de Foucault acerca del concepto clásico de la parresía.

\subsection{La parresía: Foucault y el coraje de decir la verdad (autobiográfica)}

El propio Alberca menciona a Foucault y sus estudios sobre la parresía para explicar una posible línea de investigación relacionada con esta poética de la antificción, pero hay que aludir a un artículo previo (Luque Amo, 2017) para explicar en qué consiste lo que el filósofo francés bautizó como el coraje de la verdad.

En su última etapa, Foucault llevó a cabo un minucioso acercamiento a las relaciones entre verdad y discurso en los textos personales de la época grecolatina. Allí Foucault desarrolla el concepto de parresía, que va a ser uno de los puntos fundamentales para entender su consideración de las llamadas por Foucault "literaturas del yo" (Foucault, 2003: 81). Para Foucault, la parresía es un decir todo que en realidad interpreta como un concepto mucho más amplio; para él, la parresía es "la franqueza, la libertad, la apertura, que hacen que digamos lo que tengamos que decir, como nos da la gana decirlo, cuando tenemos ganas de decirlo, y en la forma como creemos necesario decirlo" (Foucault 2005: 348). Extraído de los textos de Eurípides, en donde este le otorga un significado político, el concepto es explicado por Foucault desde dos puntos de vista: uno ético y otro técnico. Desde la perspectiva ética, el concepto de parresía es muy interesante porque podía trasladar a la época clásica todas las consideraciones éticas del pacto autobiográfico de Lejeune; desde la perspectiva técnica, resulta todavía más atractivo en la medida en que Foucault lo contrapone a la retórica como modelo de hablar franco.

En este sentido, y si bien tanto retórica como parresía tienen como objetivo producir un efecto en aquel a quien se dirigen, en el ejercicio retórico se deshace el lazo entre el que habla y lo que dice, mientras que la parresía implica un vínculo fuerte entre el emisor del discurso y su contenido. La parresía es, en este sentido, la transmisión desnuda de la verdad misma. Este vínculo entre quien habla y lo que dice conlleva, por tanto, una suerte de compromiso que Foucault describe como "un pacto determinado entre el sujeto de la enunciación y el sujeto de la conducta" (Foucault, 2005: 380).

Este pacto no es exactamente el pacto de Lejeune, porque se trata del "pacto del sujeto hablante consigo mismo" (Foucault, 2009: 81), e implica una suerte de valentía que es la de aquel que se compromete a decir la verdad por el mero hecho de ser su verdad. Para Foucault, así, la parresía "implica cierta forma de coraje, cuya forma mínima consiste en el hecho de que el parresiasta corre el riesgo de deshacer, de poner fin a la relación con el otro que, justamente, hizo posible su discurso" (Foucault, 2010: 30).

Este coraje por decir la verdad es precisamente la herramienta que empleaba Alberca para diferenciar el texto autobiográfico del autoficcional y es el elemento que, según la tesis de este artículo, puede encontrarse en la obra última de Mario Levrero; una obra que deja muchas evidencias de esa parresística lucha por la verdad autobiográfica.

\section{La autobiografía diarística de Mario Levrero}

\subsection{La obra diarística de Mario Levrero}

La obra literaria de Mario Levrero, autor de cierta peculiaridad y desigual recepción ${ }^{4}$, se ha revalorizado durante los últimos años en el contexto de las letras hispánicas. A partir de La novela luminosa y el reconocimiento de críticos como Ignacio Echevarría, su obra literaria ha ganado prestigio en los mercados europeo y latinoamericano. Mario Levrero es conocido especialmente por esta última novela, incluida en la antología preparada por el propio Ignacio Echevarría denominada Los libros esenciales de la literatura en español (Echevarría, 2011), y por sus tres novelas recogidas en la llamada trilogía involuntaria.

${ }^{4}$ Si bien en un comienzo Levrero obtuvo una rápida acogida crítica con sus primeras novelas, adscritas a lo que Ángel Rama describió (Rama, 1972: 221) como una generación nueva en la literatura uruguaya, opuesta a la generación crítica, la rareza de su escritura propició que pasara desapercibido en la escena literaria de las décadas siguientes y sufriera un reconocimiento tardío. 
Pese a que la primera parte de su producción narrativa está protagonizada por la presencia de lo novelístico, a partir de los años ochenta Levrero frecuenta otros tipos de escritura con el objetivo de introducir en su obra una profunda carga introspectiva y autobiográfica, al tiempo que empieza a cuestionar los límites genettianos (Genette, 1993) entre lo factual y lo ficcional. La herramienta que emplea para ello es la escritura diarística, que como el propio autor explica aparece como un método casi disciplinario en su modo de trabajar; Levrero emplea el diario como entrenamiento cotidiano de su prosa. El editor de Mario Levrero en España, Marcial Souto, explica los motivos del cambio que se produce en la obra narrativa del uruguayo. Señala Marcial Souto que el traslado de Levrero a la ciudad de Buenos Aires en 1985, así como las secuelas que le deja una operación de vesícula y también el intento frustrado de hacer una nueva novela, son los detonantes que lo conducen a descubrir "un instrumento hecho a su medida: la entrada de diario, que le permite transmitir cualquier cosa con naturalidad, sin demasiada elaboración, como si conversara con el lector" (Souto, 2013: 12).

Pueden localizarse, en total, tres textos diarísticos en la producción narrativa de Levrero: Diario de un canalla (1992), El discurso vacío (1996) y el "Diario de la beca", ubicado dentro de La novela luminosa (2005). Lo interesante de estos diarios en relación a la producción levreriana es que si Levrero desarrolla una obra ficcional-novelística durante los años setenta y ochenta, en donde lo fantástico - entendido, sobre todo, como subversión del espacio real, o de la escritura referencial-realista, a partir de un efecto de extrañamiento (Olivera, 2008: 125, 176, 474)-, se configura como la vertiente temática más relevante, la aparición de sus textos autobiográficos no va a conllevar un corte radical con la producción anterior. En esta evolución hay nexos entre la producción primera y la producción última de Levrero, y en última instancia va a ser lo referencial una de las características de su obra novelística, por un lado, y la inclusión de elementos propios de la narrativa fantástica en su obra autobiográfica, por otro.

A su vez, hay un nexo evidente en estos tres textos diarísticos. Así, tanto el Diario de un canalla como El discurso vacío son precedentes de La novela luminosa, en la medida en que comparten ejes temáticos con esta última. El propio Levrero lo reconoce en el prólogo a La novela luminosa cuando señala que "estos textos son también de algún modo continuación de la novela luminosa" (Levrero, 2008: 19), y lo cierto es que en todos estos textos hay una intención parecida: una apuesta por intentar decir la verdad autobiográfica. Por ello, merece la pena acercarse de forma conjunta a estos tres textos diarísticos que mantienen una línea común — hasta el punto de que Corbellini los ha definido como una "trilogía luminosa" (Corbellini, 2011) en tanto que ejemplos de la apuesta autobiográfica de Levrero en la última parte de su obra.

La tesis, en este sentido, es clara: en oposición a algunos acercamientos que inciden en el carácter autoficcional de la escritura diarística de Levrero (Corbellini, 2011; Núñez Fernández, 2011; Casas, 2011) u otros que proponen tal relación (García, 2015), este trabajo desarrolla el carácter autobiográfico de una escritura que ante todo apuesta por la intención de contar la verdad. Hay algunos artículos que ya inciden en este punto de vista autobiográfico (Olivera, 2010; Martínez Sánchez, 2016), e incluso alguien como Helena Corbellini se desdice de su artículo de 2011 para publicar recientemente un ensayo que explora esta vía autobiográfica (Corbellini, 2018), pero ninguno desarrolla las posibilidades del discurso de Levrero para aclarar los límites y diferencias entre autobiografía y autoficción en la línea de Alberca, lo que da cuenta de la originalidad de este enfoque.

\subsection{Diario de un canalla}

El primer diario de Levrero es Diario de un canalla, que escribe entre 1984 y 1986 en Buenos Aires y publica en primer lugar como un relato integrado en una colección de cuentos, El portero y el otro, en 1992. Aunque el comienzo del texto es dubitativo y se construye con la única intención de "decir por lo menos algo de lo mucho que tengo para decir, aunque no sepa por dónde empezar" (Levrero, 2013: 21), su naturaleza diarística se evidencia al valorar el formato, pues se trata de entradas fechadas, y el contenido, dado que Levrero propone un texto de autoformación en el que, con el objetivo de evitar un bache creativo, pretende registrar su cotidianidad. A semejanza de otros diaristas como Alejandro Sawa, el diario le sirve a Levrero como una herramienta de autoconocimiento ${ }^{5}$. El primer paso para este ejercicio se consigue por medio de una confesión: "Lo primero que surge es la necesidad de confesar mi condición actual [...]. Lo que debo

\footnotetext{
5 Al hablar de autoconocimiento nos referimos a una función del diario como conjunto de notas destinado a registrar la formación de una personalidad. Alejandro Sawa lo explica con claridad al comienzo de su diario: "[...] me he puesto a escribir estas hojas de mi dietario. Lo mismo me propongo hacer todos los días; luego repartiré mis jornadas en zonas de acción paralelas, aunque heterogéneas; y digo que paralelas, porque todas han de estar influidas por el mismo pensamiento que me llena por completo: la formación de mi personalidad" (Sawa, 2004: 35-36).
} 
confesar es que me he transformado en un canalla" (Levrero, 2013: 21). Y a medida que avanza en la redacción de sus primeras entradas se da cuenta de lo que está escribiendo, que, además de ser una autoconfesión, tiene un formato claro: "Porque los aparentes azares han determinado que hoy comenzara a pensar en esto como en un diario" (Levrero, 2013: 25).

Pese a que más adelante duda de este propio formato, Levrero plantea, pues, un diario personal clásico que le sirve como instrumento en el que exponer todas sus angustias vitales, sus reflexiones existencialistas y sus extrañas vivencias cotidianas. En este Diario de un canalla, además, Levrero inicia alguno de los ejes temáticos que va a exponer en La novela luminosa: así la aparición de la paloma, a través de la cual Levrero construye la identificación con el Espíritu.

Un elemento de mayor interés que el anterior, el cual será desarrollado a propósito de La novela luminosa, es la manifestación de una poética determinada en algunos pasajes. Entre otras cosas, Levrero regala un fragmento que ha sido muy citado:

Pero no estoy escribiendo para ningún lector, ni siquiera para leerme yo. Escribo para escribirme yo; es un acto de autoconstrucción. Aquí me estoy recuperando, aquí estoy luchando por rescatar pedazos de mí mismo que han quedado adheridos a mesas de operación (iba a escribir: de disección), a ciertas mujeres, a ciertas ciudades, a las descascaradas y macilentas paredes de mi apartamento montevideano, que ya no volveré a ver, a ciertos paisajes, a ciertas presencias. Sí, lo voy a hacer. Lo voy a lograr. No me fastidien con el estilo ni con la estructura: esto no es una novela, carajo. Me estoy jugando la vida (Levrero, 2013: 25).

Aquí se encuentra gran parte de la tesis que pretende sostener este artículo: la prosa diarística de Levrero no es tanto un juego posmoderno autoficcional como una apuesta real por expresar la verdad autobiográfica, al precio que sea, en todo momento. En relación a los argumentos expuestos en este artículo, no puede haber una mejor definición del coraje de la verdad: Levrero se está jugando la vida y pide la libertad de palabra, no atada a ningún tipo de condicionante retórico como pueden ser las reglas que impone el formato de la novela. En esa libertad de palabra está la esencia de la parresía, que según Foucault era "una libertad que nos da derecho a ejercer nuestros privilegios en medio de los otros, con respecto a los otros y sobre los otros" (Foucault, 2010: 51). En este párrafo de Levrero se halla toda una poética del decir veraz que se desmarca de esa duda posmoderna de la autoficción. En ese "lo voy a hacer. Lo voy a lograr" hay una clara firma de compromiso consigo mismo que al mismo tiempo es una firma con el "supuesto lector" que nombra más tarde. Levrero firma consigo mismo un compromiso de realizar una ethopoiesis, como la denomina Foucault (2010: 41), una autoconstrucción del sujeto en el texto, a partir de un discurso determinado por el hablar franco de la parresía. La franqueza del decir libre. A lo largo del texto, esta franqueza se hace patente en el estilo de las entradas diarísticas, que abunda en la cotidianidad de Levrero y en sus pensamientos íntimos, de tal manera que hay una construcción de lo íntimo y de lo privado que propicia el desarrollo del Yo. Algo que se corroborará en los siguientes textos diarísticos.

\subsection{EI discurso vacío}

El discurso vacío problematiza el debate entre la autoficción y la autobiografía desde un primer momento, en la medida en que Levrero define esta obra como una novela "construida a semejanza de un diario íntimo" (Levrero, 2004: 5). En la nota previa a la obra, sin embargo, este distingue dos tipos de textos: "uno de ellos, titulado «Ejercicios», es un conjunto de ejercicios caligráficos breves, escritos sin otro propósito; el otro, titulado «El discurso vacío», es un texto unitario de intención más «literaria»" (Levrero, 2004: 5). Aunque a raíz de las palabras de Levrero pueda deducirse que se trata de un texto mixto, compuesto de retazos referenciales y ficcionales, con dos discursos híbridos, en realidad se trata de un diario personal al uso, con todos los elementos que le corresponden, si bien ciertas estrategias retóricas lo convierten, a ojos de Levrero, en una novela. Esto, como se verá, se convierte en una suerte de escudo - casi una captatio benevolentiaecontra el inevitable destino comercial de toda obra narrativa literaria de la época: ser catalogado de novela. Una idea que Levrero repite en La novela luminosa.

Hay numerosos elementos que inducen a pensar en esta obra como un diario personal que respeta las convenciones autobiográficas. Estos ejercicios son así un tipo de escritura caligráfica, de mejora grafológica, que devienen poco a poco en algo parecido a un entrenamiento terapéutico similar al acontecido en Diario de un canalla. El tono es íntimo - se introducen relatos privados de todo tipo; desde un ataque cerebral de su madre hasta las andanzas de su compañera Alicia - y la estructura formal del texto, a su vez, incide nuevamente en las convenciones del género diarístico: entradas fechadas y el tiempo narrativo de lo que Genette denominó una narración intercalada. 
¿Qué elementos, por el contrario, llevarían a pensar en algo más, en algo similar a una novela autoficcional? La clave, para Levrero, está en la presencia de un discurso concreto, elegido, seleccionado, que en este caso se produce en las entradas tituladas bajo el epígrafe "El discurso vacío". La poética de este texto podría entenderse a partir del párrafo siguiente: "En cierto momento, y no hace mucho tiempo, el ejercicio caligráfico diario estuvo a punto de volverse un ejercicio literario. Tuve la fuerte tentación de transformar mi prosa caligráfica en prosa narrativa" (2004: 30). Esta prosa narrativa se lleva a cabo en El discurso vacío con la aparición de un perro. Mediante el perro, el gato y otros animales, Levrero pretende construir un discurso más reglado que el discurso libre del diario personal. En este discurso el perro es una excusa, un símbolo, para pergeñar una búsqueda del Yo.

Ahora bien, esta búsqueda y construcción textual del Yo es muy parecida a la afrontada en las entradas puramente diarísticas. Así, las entradas de "El discurso", que se dan exclusivamente en la segunda parte de la obra, apenas ofrecen diferencias temáticas con las diarísticas; su estructura formal es idéntica - entradas fechadas - y solo el matiz narrativo - algunos cambios en el uso de la tercera persona en pretérito para describir el relato del perro - revelan una intención más novelística. Además, las entradas puramente diarísticas se siguen sucediendo, e incluso prosiguen el relato de los "Ejercicios", como esta: "La agencia no me negó el aumento que pedí por mis crucigramas; directamente suprimió el servicio. Según el fax, hicieron cuentas y vieron que no les resultaba, ni siquiera al precio habitual. Así que estoy sin trabajo" (Levrero, 2004: 76).

En definitiva, y más allá de ese orden que Levrero impone para narrar ciertos sucesos autobiográficos que relaciona con la formación de su personalidad - y que se contrapone a esa escritura puramente referencial y terapéutica de los ejercicios-, las dos escrituras coinciden en su naturaleza autobiográfica y ethopoiética. Los paralelismos con la escritura parresística, con el decir veraz foucaultiano, son evidentes. Levrero no espera así un lector más allá de él mismo: "Lo que no puedo hacer es pensar en un lector distinto de mí; a otros lectores posibles temería aburrirlos con páginas y páginas llenas de nada, someterlos a mi propia espera disimulada" (2004: 38). Y, lo que resulta más interesante para nuestro propósito, en ningún momento renuncia a su capacidad para desarrollar un discurso verdadero:

El discurso, pues, se fue llenando con la historia del perro; es un contenido falso, o por lo menos falso a medias, ya que muy bien esos contenidos pueden ser, como todas las cosas, tomados como símbolos de otras cosas, más profundas; pienso que, en verdad, difícilmente un discurso — salvo un discurso político—, un discurso cualquiera, encarado con honestidad, pueda presentar contenidos falsos (Levrero, 2004: 44).

Si bien aquí asume las posibilidades metafóricas del relato de los animales como representaciones de su Yo, lo cierto es que está comprometiéndose de la forma más clara posible a decir verdad, asumiendo que su texto está concebido con la "honestidad" del que solo pretende "recuperar el contacto con el ser íntimo". Algo que coincide con lo explicado en la nota previa, en la que, a pesar de hablar de su texto como una novela, reconoce que es "fiel" a los diarios originales (Levrero, 2004: 5). Aquí está esa voluntad de expresar la verdad autobiográfica que era la base del Diario de un canalla y que va a ser una evidencia en La novela luminosa.

\subsection{La novela luminosa}

La novela luminosa es la gran obra narrativa de Mario Levrero. Como ocurría con El discurso vacío, La novela luminosa está dividida en dospartes claramente diferenciadas: el "Diario de la beca" y "La novela luminosa". Ese "Diario de la beca", cuyo nombre hace referencia a la beca Guggenheim recibida por Levrero para realizar la obra, es en principio el diario de preparación de la novela; texto que paradójicamente se convierte en la parte principal del libro, con más de 400 páginas de diario frente al poco más de centenar que acaban componiendo el texto propiamente novelístico, titulado "La novela luminosa". Siendo en principio, por tanto, dos partes claramente diferenciadas, lo cierto es que en ocasiones parecen textos conectados, como el propio Levrero indica: "En algún momento de estos días pensé que estaba mezclando el diario con el proyecto, y no estaba seguro de que estas páginas no correspondieran más bien a la novela luminosa" (Levrero, 2008: 378-379). El fenómeno que se produce en la obra es muy similar a lo ocurrido en El discurso vacío: el discurso diarístico contamina el discurso aparentemente literario. En este caso, las diferencias temáticas son escasas; a su vez, desde un punto de vista formal la única diferencia entre ambas es la datación temporal de las entradas del "Diario de la beca" y el carácter más reglado, ordenado y más cercano a la autobiografía de "La novela luminosa". No obstante, bastará en estas páginas el análisis del "Diario de la beca", que es el único texto que se conforma como un diario personal.

En el "Diario de la beca", Levrero desarrolla, como se ha dicho, casi todos los elementos ya esbozados en sus dos textos diarísticos anteriores. La poética inicial es parecida, al conformarse como un ejercicio a partir 
del cual Levrero pretende "poner en marcha la escritura, no importa con qué asunto, y mantener una continuidad hasta crearme el hábito" (Levrero, 2008: 23). El ejercicio cotidiano le sirve así como excusa para confeccionar un texto diarístico puramente autobiográfico. En esta línea, ofrece una referencia intertextual muy ilustrativa, como es el diario personal de Rosa Chacel, Alcancía, publicado en 1982. Este texto es uno de los diarios personales más emblemáticos de la literatura española y su recurrente aparición en el texto de Levrero revela su intención: además de conformarse como una especie de gemela literaria para el Yo del texto, Alcancía es el texto que, según confiesa Levrero, le mueve a escribir, lo que es un elemento importante para entender la naturaleza de diario personal del "Diario de la beca".

A ello se le añade, en último lugar, una cita que confirma esta naturaleza de diario personal puro:

Hoy también me desperté con la determinación de no releer lo que lleve escrito en este diario, al menos no con frecuencia, para que el diario sea diario y no una novela; quiero decir, desprenderme de la obligación de continuidad. De inmediato me di cuenta de que será igualmente una novela, quiera o no quiera, porque una novela, actualmente, es casi cualquier cosa que se ponga entre tapa y contratapa (Levrero, 2008: 26).

Con estas palabras, en las que asegura que ese texto es un diario, Levrero firma el pacto de compromiso con el lector. Incluso la segunda frase incide en la misma idea: si lo que escribe se acaba publicando como una novela, no es tanto por el hecho de que juegue con los límites referenciales de la escritura de la verdad, sino por motivos comerciales. Aquí Levrero está, de hecho, situándose con Alberca en su denuncia de lo autoficcional como mera herramienta del mercado literario. Su renuncia a las leyes del mercado, en este sentido, es una renuncia puramente comercial, no literaria, porque en ningún momento renuncia a ese compromiso de verdad autobiográfica. Todos los elementos del texto inducen a pensar en ello; Levrero habla de su texto como un diario -incluso lo tilda de diario íntimo (Levrero, 2008: 99) - y detalla todos los elementos pragmáticos de su desarrollo: su escritura a mano, su lectura de las entradas antiguas del diario a la que al principio se resiste- o el pasado a limpio del texto en el ordenador.

¿Qué es aquello que podría problematizar esta naturaleza referencial? Como ocurría con los textos diarísticos anteriores, en La novela luminosa aparecen determinados elementos que podrían interpretarse desde un punto de vista simbólico-literario: tal es el caso de la aparición de los animales, el espíritu, el fantasma, y ciertos juegos que Levrero desarrolla creado una atmósfera absurda cercana a sus primeras novelas - aunque es cierto que se trata de elementos que en el terreno novelístico poseen una función diferente a su utilización en el espacio diarístico- . Tal atmósfera se mueve entre lo onírico, lo cotidiano y lo fantástico; en este caso, se trata de esa búsqueda del espíritu que Ignacio Echevarría entiende como la obsesión central de la obra levreriana (Echevarría, 2008: 95) y que es el tema común en los tres diarios. El propio Levrero explica la genealogía de este tema en una entrada, cuando evoca el Diario de un canalla para recordar el tema de la paloma muerta (2008: 201), y da cuenta de la utilización de estos símbolos ${ }^{6}$. En $L a$ novela luminosa, el símbolo que con más fuerza problematiza la realidad es la inserción de un fantasma que Levrero asegura haber visto.

Ahora bien, si estos símbolos de Levrero son muy interesantes para desarrollar los límites entre lo referencial y lo fantástico, en numerosas ocasiones Levrero se encarga de clarificar el contexto de sinceridad en su escrito autobiográfico, reconociendo que "lo cierto es que a veces la llamada realidad objetiva se hace presente con un fuerte carácter simbólico" (Levrero, 2008: 201). Ocurre así, por ejemplo, con la aparición del fantasma, cuya presencia se narra siempre desde un Yo que escribe en tono puramente autobiográfico. En La novela luminosa, por tanto, si bien hay narraciones que inducen a lo simbólico ficcional, lo que se narra es una "realidad objetiva".

Hay que aclarar que lo anterior, sin embargo, no implica que Levrero renuncie a las posibilidades literarias del texto diarístico. Aunque una de sus obsesiones es la posible incapacidad de su diario para ser

${ }^{6}$ El fin de la obra última de Levrero, que además justifica el carácter autobiográfico de la narración, es esa búsqueda del espíritu. Levrero señala así: "Me preocupa mucho la idea de que mi espíritu esté muerto — al menos, el espíritu que me llevó a escribir la novela luminosa en 1984 _" (2008: 202). Esa búsqueda de lo sobrenatural en lo cotidiano define perfectamente el intento de Levrero por problematizar lo real; sin embargo, la ruptura que implica lo fantástico nunca se produce, y tales elementos son introducidos como particularidades de una realidad objetiva, tal y como se explica a continuación. 
leído por un lector ajeno a él ${ }^{7}$, a lo largo del texto se ve cómo esta opinión cambia, hasta jugar con la posibilidad de que sea leído como una novela:

En casa, M aceptó leer el primer capítulo (agosto) de este diario. Yo estaba seguro de que iba a abandonar la lectura a las pocas páginas, pero no; leyó todo, hasta el final, y con mucha atención [...]. Le pregunté si no sería que leyó con interés por esa curiosidad que tenemos todos, y especialmente las mujeres, por detalles íntimos de los demás. Dijo que seguramente sí, pero que, hasta donde era capaz de discriminar, aunque es difícil hacerlo, también había un interés literario. Y me comentó algunos pasajes que la habían entusiasmado, o al menos conmovido. Después me llamó por teléfono desde su casa, para hacer un comentario más: dice que para el lector común, tal vez este diario podría pasar por una novela, con un protagonista y unas situaciones inventadas por mí. Me gustó el comentario. Esto me da impulso para seguir trabajando (Levrero, 2008: 365-366).

En este párrafo está condensada la poética autobiográfica de estos textos: son textos con una clara naturaleza referencial que, una vez diluidos sus referentes en la narración, pueden interpretarse y ser leídos como literatura. Ante esta última posibilidad, sin embargo, no cabe acercarse con temeridad o con la duda posmoderna de que lo literario imposibilite el compromiso de verdad autobiográfica. Por el contrario, no hay ningún momento en toda la obra que Levrero desfallezca en su intento de decir verdad. Esto se demuestra con más claridad en una de sus entradas finales, en donde declara:

Tengo un gran problema con este diario; antes de dormir pensaba que por su estructura de novela ya tendría que estar terminando, pero su calidad de diario no me lo permite, sencillamente porque hace mucho tiempo que no sucede nada interesante en mi vida como para llegar a un final digno [...]. Se me ocurrió pensar que debería hacer algo; ya que no aparece nada novedoso, ningún cambio, ninguna sorpresa interesante, debería tomar yo la iniciativa y generar un tema decoroso para el final. Después pensé que no era lícito. Yo no puedo salir a la calle disfrazado de mono para generar una historia divertida y distinta con la cual terminar el libro; no puedo empezar a vivir en función del diario y de esa necesidad de completarlo (Levrero, 2008: 433-444).

Aquí Levrero está confirmando una vez más el compromiso de verdad autobiográfica que adquiere al declarar estas páginas como su diario: no se trata solo de no mentir, es que la honestidad de su discurso definido por él mismo, más arriba, con esa misma palabra: honestidad - le impide, incluso, adulterar la realidad que vive para confeccionar un discurso autobiográfico que le permita construir un final a la altura de una ficción novelesca.

$\mathrm{Si}$ a algo renuncia aparentemente Levrero, en este sentido, es más bien a esa estructura de novela a la que en todo momento aspira. En la última entrada de la obra, el epílogo que Levrero firma después de "la novela luminosa", explica lo siguiente:

Un diario no es una novela; a menudo se abren líneas argumentales que luego no continúan, y difícilmente alguna de ellas tenga una conclusión nítida. Me hubiera gustado que el diario de la beca pudiera leerse como una novela; tenía la vaga esperanza de que todas las líneas argumentales abiertas tuvieran alguna forma de remate. Desde luego, no fue así, y este libro, en su conjunto, es una muestra o un museo de historias inconclusas (Levrero, 2008: 561).

Asumida esta renuncia, eso sí, en ningún caso parece Levrero obviar lo que de literatura tiene ese "museo de historias inconclusas". Levrero firma de principio a fin el pacto de verdad con su lector y al mismo tiempo es consciente de la capacidad de su texto para, si acaso no ser leído desde las reglas de la novela, ser leído como una suerte de literatura de lo cotidiano, de una literatura del aburrimiento, como el propio Levrero bautiza irónicamente (Levrero, 2004: 28). De tal manera que, en última instancia, el único perdedor es el género novelístico.

\footnotetext{
${ }^{7}$ Señala: "Hace unos días comencé a leer y corregir las erratas de este diario. Me sorprendió advertir que ahora, pasados estos meses, puedo leerlo con interés; no me parece una lectura tan despreciable como me parecía antes. Es difícil hacerme una idea de su interés para un lector que no sea yo, pero el hecho de que sea interesante para mí ya es mucho" (2008: 351).
} 


\section{Conclusiones}

La obra diarística de Mario Levrero, como se ha visto, es idónea para arrojar luz en el debate sobre escritura autobiográfica y autoficcional. A partir del análisis de estos diarios pueden desarrollarse las principales ideas expuestas por Manuel Alberca en su teoría sobre la antificción. Es difícil encontrar autores que, a pesar de concebir textos cuyos límites entre lo novelístico y lo autobiográfico son problemáticos, demuestren con más claridad ese compromiso de honestidad. Cuando Levrero señala que lo que escribe "no es una novela" y que se está "jugando la vida", está exponiendo una visión de lo autobiográfico como apuesta ética del decir verdad sobre sí mismo. Más allá de los debates posmodernos sobre la imposibilidad de lo autobiográfico solo asumibles desde coordenadas deconstruccionistas-, debe ser destacado el deseo del autor por comprometerse con su propia verdad autobiográfica. Manuel Alberca resume esa generosidad del autobiógrafo en lo siguiente:

Con sus verdades y mentiras, con sus buenas intenciones y sus trampas, (...) los relatos autobiográficos auténticos son observatorios privilegiados para entender, con fundamento real, las complejas y contradictorias razones del ser humano. Nos permiten conocer también, si el ejercicio es sincero, de primera mano a la persona que lo escribe, y en su claroscuro le revela al lector sus propias luces y sombras. Por eso hay que agradecerle al autobiógrafo el esfuerzo y el riesgo que corre por ser veraz (Levrero, 2017: 333).

El riesgo asumido por el escritor conlleva el coraje de la verdad que asume el parresiastés, el que se atreve a acercarse con la sinceridad necesaria al relato de uno mismo.

En el caso de Levrero, como se ha sugerido, no son pocas las aproximaciones a su obra diarística desde un punto de vista autoficcional: sucede así con los artículos de Núñez Fernández (2011) y Mariano García (2015), por citar dos ejemplos. Núñez Fernández, si bien acepta que la obra de Levrero "reclama en el lector un marco de recepción basado en la asunción de estar frente a la declaración de una instancia intimista sincera" (Núñez Fernández, 2011: 306), relaciona constantemente esta con la autoficción y la define como "el contar las fantasías personales a través de los recursos propios de la novela introspectiva y monológica" (Núñez Fernández, 2011: 303). Mariano García, por otro lado, incide en el carácter irónico de estos textos para destacar que "oscilan entre la metaficción y la autoficción, el desgarramiento autoral entre destruir la ilusión ficcional o realzarla" (García, 2015: 147) y privilegiar en todo momento el género autoficcional sobre el autobiográfico. Aunque algunos de los motivos que exponen estos autores son razonables, al incidir en el constante juego de Levrero, también resultan incompletos: Levrero ofrece un marco dudoso para sus diarios, que intenta disfrazar de novela - es el caso de El discurso vacío, sobre todo; el "Diario de la beca" solo problematizaría su marco al estar inserto dentro de La novela luminosa, mientras que el Diario de un canalla nunca estaría catalogado como novela-, pero en última instancia siempre resulta un ejercicio fallido, por cuanto triunfa sobre ellos lo autobiográfico. En este sentido, ninguno de los dos autores apunta al fracaso de las estrategias retóricas de la obra diarística de Levrero, quien renuncia en repetidas ocasiones a la forma novelesca, base de la autoficción, de modo que ignoran la novela fracasada y la autobiografía triunfante que es la obra de Levrero ${ }^{8}$.

Por lo tanto, los dos artículos citados tienen, a nuestro parecer, el mismo problema: aunque aciertan al sugerir la libertad del Yo textual respecto del Yo real ${ }^{9}$, no desarrollan - al menos pormenorizadamente- el hecho de que las posibilidades literarias del texto diarístico en Levrero, aún existiendo, no anulan sus posibilidades autobiográficas. En la pugna inevitable entre autobiografía y autoficción, Levrero no renuncia en ningún momento al decir verdad de la primera; por el contrario, sí renuncia a la invención puramente ficcional de la novela, como se ha visto en el anterior punto y se vuelve a comprobar en el siguiente pasaje:

\footnotetext{
${ }^{8}$ Un tercer caso que puede añadirse es el de Helena Corbellini. Esta autora, que si bien en 2011 (Corbellini, 2011) situaba la obra levreriana en un terreno difuso, más cercano a lo autoficcional según lo que se puede deducir de las continuas alusiones a Gasparini y Paul de Man, en 2018 (Corbellini, 2018) ha publicado un ensayo que prima la interpretación autobiográfica. En una entrevista reciente señala una tesis parecida a la expuesta en este artículo: "Tras todas mis lecturas, entiendo que solamente en Uruguay la crítica confunde autobiografía con autoficción. [...] el hombre que se narra y que exclama "esto no es una novela, carajo" o "me estoy jugando la vida", como hace Levrero, ¿qué está haciendo? Tiene la pretensión de decir la verdad sobre sí mismo. No es la verdad referencial exterior, esa poco importa para el objetivo; la importancia está en la revelación de su ser íntimo, en el estallido de su subjetividad", en https://findesemana.ladiaria.com.uy/articulo/2018/9/mi-pacto-con-levrero/

${ }^{9}$ Como se comentaba en la introducción, es innegable que el texto siempre implica cierta independencia del Yo; el Yo textual siempre va a ser un Yo derivado del Yo empírico, no el Yo empírico en sí.
} 
El otro día comprobé que podía escribir, si quería, aunque me fueran a interrumpir; puedo escribir, al menos, este diario, que no exige mayor concentración porque apenas si uso la imaginación y escribo al vaivén más o menos errático de mi pensamiento; es posible que si intentara escribir un relato o una novela, ahí sí, el temor a ser interrumpido me inhibiera por completo (Levrero, 2011: 66).

En este sentido, autoficción es una etiqueta que resulta insuficiente para definir el texto de Levrero: el escritor uruguayo no pone en duda su compromiso referencial como sucede con los escritores de autoficción; no hay ningún motivo para pensar en la invención de los hechos narrados y la cuestión de la identificación nominal, que Corbellini añade, es irrelevante en tanto que aparece el nombre de Mario Levrero en el texto ${ }^{10}$. Los diarios de Levrero, entonces, van mucho más allá del juego autoficcional de la novela moderna y aunque puedan leerse, dado el carácter performativo de todo Yo textual, como literarios- no tienen ningún miedo al compromiso que la autobiografía implica.

Existe en estos diarios, por último, una apelación constante al lector que completa el pacto entre emisor y receptor y que se relaciona otra vez con el concepto de la parresía. Señalaba Foucault, así, que "si el parresiasta muestra su coraje al decir la verdad con respecto a todo y contra todo, aquel a quien esa parresía se dirige deberá mostrar su magnanimidad aceptando que se le diga la verdad" (Foucault, 2010: 32). En los diarios, Levrero alude en todo momento a un posible lector ${ }^{11}$ y lo hace, por medio de la captatio benevolentiae continua, en un tono de compromiso de verdad muy claro. Así, evidencia un pacto que es aquel de quien lucha por expresar su verdad autobiográfica ante alguien, un pacto que se asemeja al propuesto por Lejeune (1994) y que, en última instancia, lo que busca es garantizar la verdad de lo narrado.

Mario Levrero confecciona, en definitiva, una propuesta diarística basada en la honestidad de quien se describe sinceramente a sí mismo ante un lector. Cuando Levrero señala que "esto es mi diario y puedo escribir lo que quiera" (Levrero, 2008: 137) está esgrimiendo su libertad creativa como un derecho del autobiógrafo, aludiendo a su vez a una de las características principales de la parresía foucaultiana, que es la de la libertad de palabra sobre uno mismo. Esta libertad es la que permite hacer eso que Alberca propone tímidamente como antificción y que a fin de cuentas no es otra cosa que la autonomía del autor que se compromete a decir verdad sobre sí mismo y, precisamente por ello, es libre. Levrero utiliza esta libertad para construir unos diarios que, si bien literarios, no son autoficcionales; por el contrario, y a pesar de las vacilaciones en el uso de las etiquetas comerciales ${ }^{12}$, son claramente autobiográficos. De tal manera que, en última instancia, la obra diarística de Levrero se inscribe en la tradición del diario literario (Luque Amo, 2016).

\section{Referencias bibliográficas}

Alberca, Manuel (2017). La máscara o la vida. De la autoficción a la antificción. Málaga: Pálido Fuego.

Bueno, Gustavo (2000). Televisión: Apariencia y Verdad, Barcelona: Gedisa.

Casas, Ana (2011), “La autoficción en los estudios hispánicos: perspectivas actuales”, en A. Casas (ed.). El yo fabulado. Nuevas aproximaciones críticas a la autoficción. Madrid-Frankfurt: Iberoamericana-Vervuert, págs. 7-21.

-----, --- (2012), "El simulacro del yo: la autoficción en la narrativa actual", en A. Casas (ed.). La autoficción: reflexiones teóricas. Madrid: Arco Libros, págs. 9-42.

Corbellini, Helena (2011), "La trilogía luminosa de Mario Levrero", Revista de la Biblioteca Nacional, 4-5, págs. 251262.

----------, ------ (2018). El pacto espiritual de Mario Levrero. Montevideo: Paréntesis.

${ }^{10} \mathrm{Si}$ bien es cierto que en Diario de un canalla y en El discurso vacío, su nombre no aparece, en el "Diario de la beca" aparece en varias ocasiones (Levrero 2008: 149, 377, 384, 402). Sí debe reconocerse cierta problemática que la elección del nombre Mario Levrero, en un autor nacido como Jorge Mario Varlotta Levrero, implica. Diego Vecchio (2016) explica esto a la perfección en su artículo "Las personalidades múltiples de Jorge Mario Varlotta Levrero". En todo caso, el juego de Levrero no problematiza los elementos pragmáticos del pacto autobiográfico de Lejeune, pues en el texto aparecen los nombres de Mario Levrero y Jorge Valotta indistintamente, aludiendo al mismo sujeto sin confusión alguna. La identificación entre autor, narrador y personaje es en todo momento evidente.

${ }^{11}$ Señala Levrero: "Yo no sé si algún lector se interesa por la indicación de fecha y hora que titula cada capitulito de este diario; cuando yo leo diarios ajenos, por lo general es como si esas indicaciones no existieran. Y para eso, Mr. Guggenheim, es necesario que, desde este diario íntimo, busque el camino de mis sentimientos reviviendo hechos más recientes, casi diría fresquitos" (2008: 99).

${ }^{12}$ Uno de los grandes preceptos del pacto autobiográfico de Lejeune es la firma del título: el autobiógrafo muestra su compromiso afirmando que eso es un diario. Como se ha visto, El discurso vacío problematiza esta firma, si bien en última instancia es un texto claramente autobiográfico. Por ello ha resultado más interesante en este artículo partir de Manuel Alberca que de Philippe Lejeune: el primero incide así en la libertad de ciertos textos para mostrar la sinceridad del Yo que se describe a sí mismo; el segundo se limita a los elementos pragmáticos. Desde el primer enfoque, que pasa por encima de ciertos detalles pragmáticos, es mucho más sencillo entender la naturaleza autobiográfica de los diarios de Levrero. 
Echevarría, Ignacio (2008). “Levrero y los pájaros”, en P. Silvia Olazábal (ed.). Conversaciones con Mario Levrero. Montevideo: Trilce, págs. 93-103.

Madrid: Lunweg.

Foucault, Michel (2003). El Yo minimalista y otras conversaciones. Buenos Aires: La marca.

---------, ------- (2005). La hermenéutica del sujeto. Madrid: Akal.

----------, ------- (2009). El gobierno de sí y de los otros. Buenos Aires: Fondo de Cultura Económica. -- (2010). El coraje de la verdad. Buenos Aires: Fondo de Cultura Económica.

García, Mariano (2015). "Las dos caras de la autoficción en La novela luminosa de Mario Levrero", Pasavento, 3/1, págs. 137-153.

Genette, Gerard (1993). Ficción y dicción. Barcelona: Lumen.

Lecarme, Jacques (1992), “Autofiction: un mauvais genre?”, Ritm, 6, págs. 227-249.

Lejeune, Philippe (1994). El pacto autobiográfico. Madrid: Megazul.

-------, ------ (2007), “Le journal comme «antifiction»”, Poetique, 149 págs. 3-14.

Levrero, Mario (2004). El discurso vacío. Montevideo: Trilce.

-------, ----- (2008). La novela luminosa. Mondadori: Barcelona.

--------, ------ (2013). Diario de un canalla. Burdeos, 1972. Mondadori: Barcelona.

Loureiro, Ángel G. (2001), “Autobiografía: el rehén singular y la oreja invisible”, Anales de literatura española, 14, págs. 135-150.

Luque Amo, Álvaro (2016), "El diario personal en la literatura: teoría del diario literario", Castilla. Estudios de literatura, 7, págs. 273-306.

--------, ------ (2017), "Literatura y autobiopolítica: aportaciones de Michel Foucault a la teoría de la autobiografía", $452^{\circ} \mathrm{F}$. Revista de Teoría de la literatura y Literatura Comparada, 17, págs. 18-35.

Man, Paul de (1991), “La autobiografía como des-figuraciónl", Anthropos, 29, págs. 113-118.

Martínez Sánchez, Rocío (2016), "Posturas del narrador en los diarios ficcionales de Mario Levrero", Tonos, 31. Disponible en: https://www.um.es/tonosdigital/znum31/secciones/perfiles-1-perfil_levrero.html\# ftn1.

Molero de la Iglesia, Alicia (2006), "Figuras y significados de la autonovelación”, Espéculo, 33. Disponible en: http://webs.ucm.es/info/especulo/numero33/autonove.html.

Núñez Fernández, Matías (2011), "Ejercicios de perspectiva del yo y discurso autoficcional en la literatura uruguaya a partir de Mario Levrero", Revista de la Biblioteca Nacional, 4-5, págs. 301-314.

Olivera, Jorge (2008). Intrusismos de lo real en la narrativa de Mario Levrero (Tesis doctoral). Madrid: Universidad Complutense de Madrid. Disponible en: http://eprints.ucm.es/8631/1/T30796.pdf

--------, ------ (2010), "Mario Levrero en sus diarios: de la ficción a la biografía”, Anales de Literatura Hispanoamericana, 39, págs. 331-347.

Rama, Ángel (1967). La generación crítica 1939-1969. Montevideo: Arca.

Ricoeur, Paul (2006), "La vida: un relato en busca de un narrador", Ágora: Papeles de filosofía, 25, págs. 9-22.

Sawa, Alejandro (2004). Iluminaciones en la sombra. Madrid: Josef K.

Souto, Marcial (2013), "Prólogo", en Mario Levrero. Diario de un canalla. Burdeos, 1972. Mondadori: Barcelona, págs. 7-13.

Vecchio, Diego (2016), “Las personalidades múltiples de Jorge Mario Varlotta Levrero", Cuadernos LIRICO, 14. Disponible en: http://journals.openedition.org/lirico/2301. 